Provided for non-commercial research and education use. Not for reproduction, distribution or commercial use.

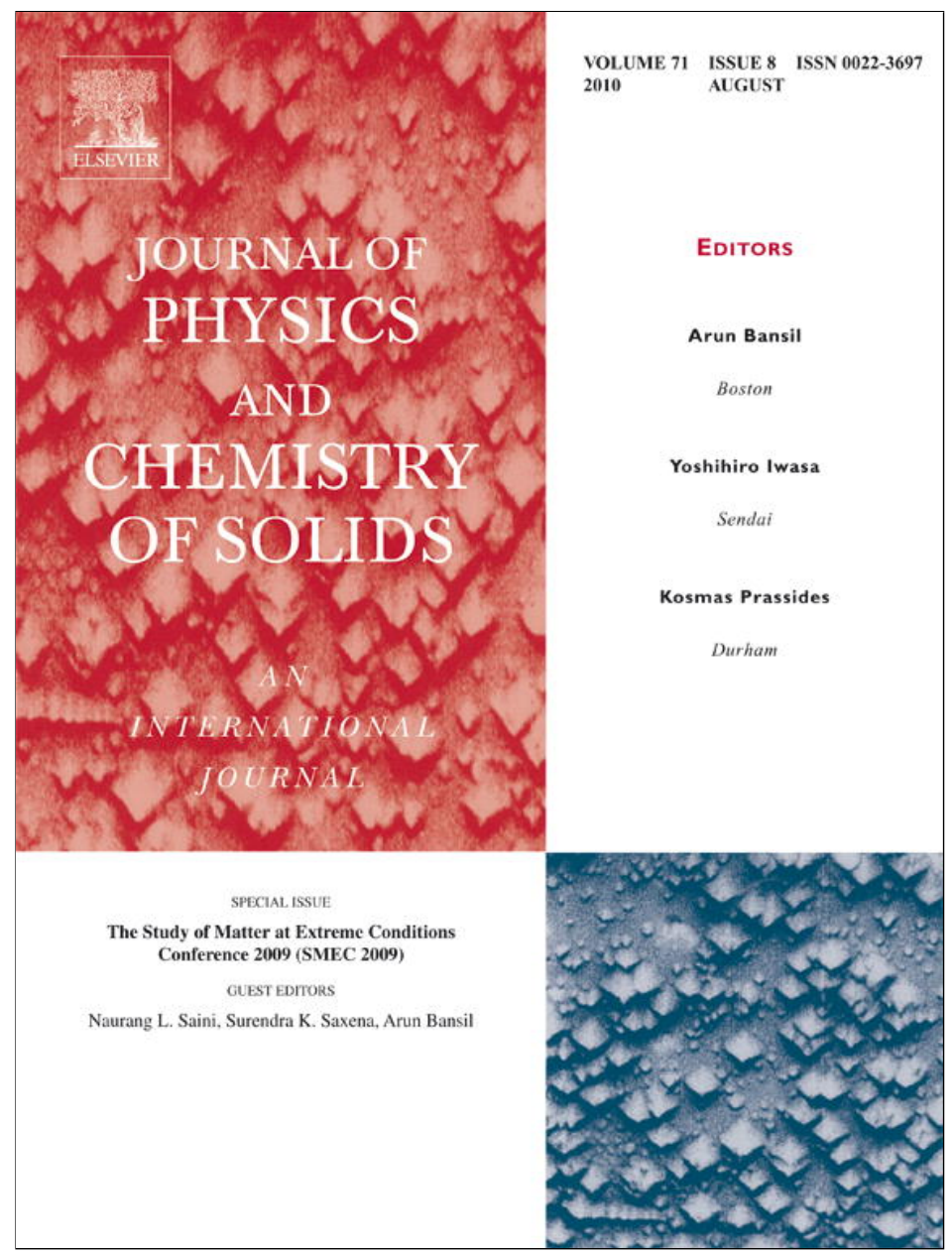

This article appeared in a journal published by Elsevier. The attached copy is furnished to the author for internal non-commercial research and education use, including for instruction at the authors institution and sharing with colleagues.

Other uses, including reproduction and distribution, or selling or licensing copies, or posting to personal, institutional or third party websites are prohibited.

In most cases authors are permitted to post their version of the article (e.g. in Word or Tex form) to their personal website or institutional repository. Authors requiring further information regarding Elsevier's archiving and manuscript policies are encouraged to visit:

http://www.elsevier.com/copyright 


\title{
Compression of silver in a diamond anvil cell: Pressure dependences of strength and grain size from X-ray diffraction data
}

\author{
Hanns-Peter Liermann ${ }^{\mathrm{a}, 1}$, Anjana Jain ${ }^{\mathrm{b}}$, Anil K. Singh ${ }^{\mathrm{b}, *}$, Surendra K. Saxena ${ }^{\mathrm{c}}$ \\ a HPCAT Bldg. 434E, Advanced Photon Source, Argonne National Laboratory, Argonne, IL 60439-4803, USA \\ ${ }^{b}$ Materials Science Division, National Aerospace Laboratories, Bangalore 560 017, India \\ ${ }^{\mathrm{c}}$ Center for the Study of Matter at Extreme Conditions (CeSMEC), Florida International University, Miami, FL 33199, USA
}

\section{A R T I C L E I N F O}

Keywords:

C. High pressure

C. X-ray diffraction

\begin{abstract}
A B S T R A C T
Two silver samples, coarse grained (c-Ag, grain size $300 \pm 30 \mathrm{~nm}$ ) and nanocrystalline ( $\mathrm{n}-\mathrm{Ag}$, grain size $55 \pm 6 \mathrm{~nm}$ ), are compressed in a diamond anvil cell in separate experiments. The pressure is increased in steps of $\sim 3 \mathrm{GPa}$ and the diffraction pattern recorded at each pressure. The grain size and compressive strength are determined from the analysis of the diffraction line-widths. The grain size of c-Ag decreases rapidly from $300 \pm 30 \mathrm{~nm}$ at ambient pressure to $40 \pm 8 \mathrm{~nm}$ at $15 \mathrm{GPa}$, and then gradually to $20 \pm 3 \mathrm{~nm}$ at $40 \mathrm{GPa}$. After pressure release to ambient condition, the grain size is $25 \pm 4 \mathrm{~nm}$. The strength at ambient pressure is $0.18 \pm 0.05 \mathrm{GPa}$ and increases to $1.0 \pm 0.3 \mathrm{GPa}$ at $40 \mathrm{GPa}$. The grain size of $\mathrm{n}-\mathrm{Ag}$ decreases from $55 \pm 6 \mathrm{~nm}$ at ambient pressure to $17 \pm 4 \mathrm{~nm}$ at $15 \mathrm{GPa}$ and to $14 \pm 3 \mathrm{~nm}$ at $55 \mathrm{GPa}$. After release of pressure to ambient condition, the grain size is $50 \pm 7 \mathrm{~nm}$. The strength increases from $0.51 \pm 0.07 \mathrm{GPa}$ at ambient pressure to $3.5 \pm 0.4 \mathrm{GPa}$ at $55 \mathrm{GPa}$. The strength is found to vary as the inverse of the square-root of the grain size. The results of the present measurements agree well with the grain-size dependence of strength derived from the hardness versus grain size data at ambient pressure available in the literature.
\end{abstract}

(c) 2010 Elsevier Ltd. All rights reserved.

\section{Introduction}

Diamond anvil cells (DACs) have been extensively used to pressurize samples and study the properties under ultrahigh pressures. On compression in a DAC, the sample-gasket assembly flows radially between the anvils and equilibrium is reached when the frictional forces between the sample-anvil interfaces balance the forces causing the flow. This results in a highly complex stress state in the sample. Two types of stresses, macro and micro, are recognized in such cases. The macro-stresses represent average stresses in a direction that cuts across large number crystallites. These stresses produce strains that cause the diffraction lines to shift. The description of macro-stresses at the center of the sample is considerably simplified by the presence of an axial symmetry about the load axis of the DAC. The stress state is completely described by three principal stresses, one along the symmetry axis and two equal stresses in the plane parallel to the anvil face. The principal stress along the symmetry axis is larger than that parallel to the anvil face and the difference between the two equals the yield strength of the solid sample at a pressure that is given by the mean normal stress [1]. The analyses of the diffraction-line shifts measured in high-pressure X-ray diffraction

\footnotetext{
* Corresponding author.

E-mail address: aksingh@nal.res.in (A.K. Singh).

${ }^{1}$ Present address: DESY, HASYLAB, Hamburg, Germany.
}

experiments on polycrystalline samples give information on the mechanical properties like yield strength and elasticity. The development of this subject can be found in a review article [2]. The micro-stresses vary randomly in direction and magnitude in each crystallite [3], and produce micro-strains that cause the diffraction lines to broaden. The product of micro-strain and an appropriate Young's modulus is a measure of the compressive yield strength of the solid sample [4-18]. It may be mentioned that the X-ray diffraction measures lattice strains that are elastic even though the sample undergoes considerable plastic deformation during pressurization. In this study, we analyze the linewidths of high-pressure X-ray diffraction patterns of silver to derive the grain size and compressive strength as function of pressure. Two silver samples of different grain sizes, c-Ag $(300 \pm 30 \mathrm{~nm})$ and $\mathrm{n}-\mathrm{Ag}(55 \pm 6 \mathrm{~nm})$, are used. The strength corrected for the pressure effect is found to vary as the inverse of the square-root of the grain size $[19,20]$. The grain-size dependence of the strength obtained in this study is compared with that derived from the hardness-grain-size data at ambient pressure available in literature [21].

\section{Experimental details}

The c-Ag sample from Johnson Matthey Chemicals used in the present experiment was of spectroscopic purity containing 
$1 \mathrm{ppm} / \mathrm{wt}$ of palladium as the major impurity. The other impurity elements (calcium, copper, iron, and magnesium) were $<1 \mathrm{ppm} /$ wt. The n-Ag sample, dark grey in color, from Sigma-Aldrich was of $99.5 \%$ purity based on trace metal analysis. The major impurities were: iron $(8.1 \mathrm{ppm})$, calcium (3.1 ppm), thallium (1.3 ppm), chromium (0.9 ppm), boron (0.6 ppm) and magnesium $(0.6 \mathrm{ppm})$. The initial grain sizes as determined from the linewidths of the high-resolution X-ray diffraction patterns taken at ambient pressure were $300 \pm 30$ and $55 \pm 6 \mathrm{~nm}$ for $\mathrm{c}-\mathrm{Ag}$ and $\mathrm{n}-\mathrm{Ag}$, respectively. A diamond anvil cell with diamond-anvil flat faces of $300 \mu \mathrm{m}$ diameter was used to compress the sample. A stainless steel gasket ( $44 \mu \mathrm{m}$ indented region with $130 \mu \mathrm{m}$ hole) was used to contain a small piece of silver. No pressure transmitting medium was used to maximize the nonhydrostatic compression effects. The diffraction experiments were carried out using the insertion device beam of the High-Pressure Collaboration Access Team (HPCAT) at the Advanced Photon Source (APS), Argonne National Laboratory, Chicago. The incident beam of wavelength $0.036633 \mathrm{~nm}$ was collimated to achieve a cross section of $13 \times 13 \mu \mathrm{m}^{2}$. The pressure was increased in steps of $\sim 3 \mathrm{GPa}$ and the diffraction pattern recorded online on an image plate at each pressure. The first eight diffraction peaks from silver could be recorded in all the pressure runs with $\mathrm{c}-\mathrm{Ag}$ and five to eight peaks with n-Ag. After reaching the highest pressure ( $\sim 40 \mathrm{GPa}$ with c- $\mathrm{Ag}$ and $55 \mathrm{GPa}$ with $\mathrm{n}-\mathrm{Ag}$ ), the pressure was reduced in steps of $\sim 10 \mathrm{GPa}$ and diffraction patterns were recorded. The pressure on the sample was computed from the measured unit cell volume of silver by using equation $\mathrm{HO} 2$ given in Table 2 of Holzapfel [22] with the values of $97.7 \mathrm{GPa}$ and 5.51 for the isothermal bulk modulus and its pressure derivative, respectively.

\section{Method of data analysis}

Stokes and Wilson [3] discussed the diffraction-line broadening assuming that the micro-stresses in the deformed crystallites vary between zero and a maximum stress $p_{\text {max }}$. We extended this model to interpret the high-pressure diffraction patterns by assuming that the stresses in the crystallites occur with equal probability between a minimum and a maximum stress, and identified the difference between the two extremes with the maximum stress $2 p_{\max }$ [11]. The standard equation [23] describing the dependence of the line width on grain-size and micro-strain can be written down as follows:

$\left(2 w_{h k l} \cos \theta_{h k l}\right)^{2}=(\lambda / D)^{2}+\left[4 p_{\max } / E_{h k l}\right]^{2} \sin ^{2} \theta_{h k l}$.

Here, $2 w_{h k l}$ is the full width at half-maximum (FWHM) on $2 \theta$-scale and $\theta_{h k l}$ is the Bragg angle. $E_{h k l}$ is the single-crystal Young's modulus in the direction $h k l$. The symbols $\lambda$ and $D$ denote the wavelength of X-rays and grain size (coherently scattering domain size), respectively. The $\left(2 w_{h k l} \cos \theta_{h k l}\right)^{2}$ versus $\left(\sin \theta_{h k l} / E_{h k l}\right)^{2}$ plot is a straight line. The intercept and slope of the line give $D$ and $p_{\text {max }}$, respectively. The term $E_{h k l}$ in Eq. (1) is computed using the relation

$1 / E_{h k l}=S_{11}-2\left(S_{11}-S_{12}-S_{44} / 2\right) \Gamma(h k l)$,

$\Gamma(h k l)=\left(h^{2} k^{2}+k^{2} l^{2}+l^{2} h^{2}\right) /\left(h^{2}+k^{2}+l^{2}\right)^{2}$.

The single-crystal elastic compliances $S_{i j}$ in Eq. (2) are at high pressure. The single-crystal elastic moduli $C_{i j}$ at high pressure are computed using Birch extrapolation formula [24] given below:

$C_{i j}=C_{i j}(0) x^{5 / 3}\left\{1+\frac{1}{2}\left[3 K(0) C_{i j}^{\prime}(0) / C_{i j}(0)-5\right]\left(x^{2 / 3}-1\right)\right\}$

The symbol (0) denotes the quantity at zero (ambient) pressure. The prime indicates the first derivative with respect to pressure, $K$ is the bulk modulus, and $x=V(0) / V, V$ being the unit cell volume. The values of $C_{i j}(0)$ and $C_{i j}^{\prime}(0)$ for silver were taken from the measurements by Daniels and Smith [25]. The earlier studies have shown that $2 p_{\max }$ is a measure of compressive strength in agreement with the strength derived from the shifts of the diffraction lines $[11,14]$.

\section{Results and discussions}

The four-parameter pseudo-Voigt function containing a linear background term was fitted to each diffraction peak and $2 w_{h k l}$ and $2 \theta_{h k l}$ were determined. The width data were corrected for the instrumental broadening by the method discussed in an earlier publication [13]. The $\left(\sin \theta_{h k l} / E_{h k l}\right)^{2}$ versus $\left(2 w_{h k l} \cos \theta_{h k l}\right)^{2}$ plot was constructed for each pressure run. The typical plots are shown in Fig. 1. The error bars (standard errors) calculated from the errors in $2 w_{h k l}$ are of the size of the symbols. The scatter of the data seen in Fig. 1 mainly comes from the difference between the assumed and actual micro-strain distributions.

It may be noted that Young's modulus $E(h k l)$ required in Eq. (1) were derived from the single-crystal elasticity data (Eq. (4)). The grain sizes encountered in this study are small. The use of singlecrystal elastic moduli to calculate $E(h k l)$ implies the assumption that the single-crystal elastic moduli do not change on reducing the grain size to a few tens of nanometer. A number of studies support this assumption. The measurements of Young's modulus on low-porosity compacts of nanocrystalline $\mathrm{Cu}$ and $\mathrm{Pd}$ showed only a small decrease from the value for coarse-grained samples [26]. This decrease was attributed to the presence of residual porosity in the samples. The high-pressure X-ray diffraction measurements and the first-principles calculations on nanocrystalline nickel showed no significant difference between the bulk moduli of nanocrystalline and large-grained nickel [27]. In another study, the bulk modulus of iron samples of $10 \mathrm{~nm}$ grain size was found to be close to that of large grained samples [28]. In a more recent X-ray diffraction study under hydrostatic pressure, the measured bulk modulus of $\mathrm{SiC}$ of $30 \mathrm{~nm}$ grain size was in agreement with that of large-grained sample [29]. This study reiterated an important point that the differences between the bulk moduli of large grained and nanograined samples often reported in the literature arise from the uncertainties in the measurements due to various factors including nonhydrostatic pressure. The first-principles atomistic calculations of the elastic properties of metallic face-centered cubic nanocrystals show that the material length scale for elasticity is small [30]. Estimates

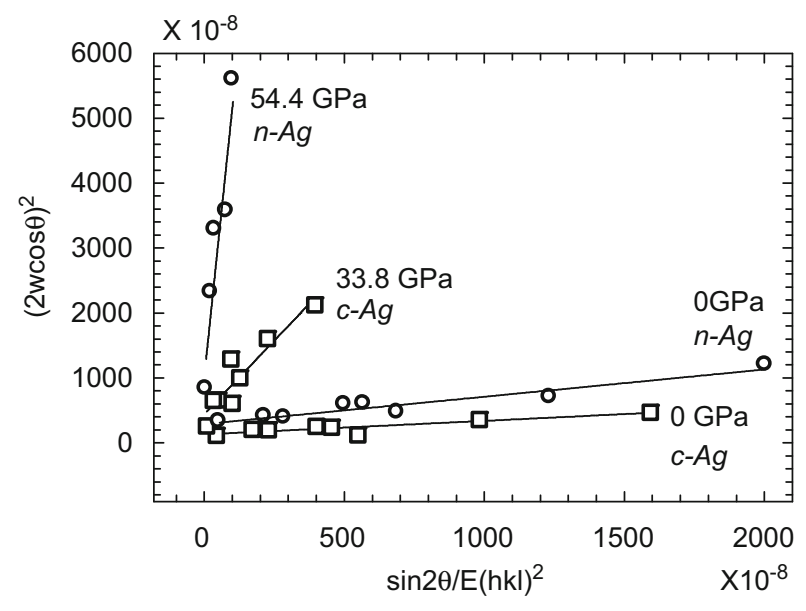

Fig. 1. Typical $\left(\sin \theta_{h k l} / E_{h k l}\right)^{2}$ versus $\left(2 w_{h k l} \cos \theta_{h k l}\right)^{2}$ plots are shown. The estimated error bars are of the size of the symbols. 
using this analysis suggest that the size effect on elasticity for silver becomes important only at grain sizes $\sim 5 \mathrm{~nm}$. These results provide ample justification for the use of single-crystal elasticity data for the analysis of diffraction patterns of silver in this study.

\subsection{Grain size}

Fig. 2(a) shows that the grain size of c-Ag decreases rapidly from $300 \pm 30$ to $40 \pm 8 \mathrm{~nm}$ in the $0-15 \mathrm{GPa}$ pressure range and gradually to $20 \pm 3 \mathrm{~nm}$ at $40 \mathrm{GPa}$ pressure. The grain size increases slightly as the pressure is reduced from $40 \mathrm{GPa}$ and reaches $25 \pm 4 \mathrm{~nm}$ at ambient pressure. Thus, the reduction in grain size during compression to $40 \mathrm{GPa}$ is largely permanent. The changes in the grain size caused by pressurization arise from two distinct sources, the compressibility and plastic deformation. The decrease in grain size due to the compressibility effect is the intrinsic material property and is small for most solids, the decrease for silver being only $\sim 7 \%$ at $40 \mathrm{GPa}$. The decrease largely arises from severe deformation of the sample during nonhydrostatic compression. The magnitude of the decrease depends on the extent of deformation the sample undergoes before a given pressure is established. For these reasons, the measured grain size under nonhydrostatic compression is not a unique function of pressure. The solids belonging to the cubic system do not undergo plastic deformation under truly hydrostatic pressure, and therefore, the decrease in the grain size is only due to the compressibility factor. The resulting increase in the diffraction-line widths is small. The diffraction experiments under hydrostatic pressure [31] support this conclusion. The grain size of $\mathrm{n}-\mathrm{Ag}$ decreases rapidly from $55+6 \mathrm{~nm}$ at ambient pressure to $17 \pm 4 \mathrm{~nm}$ at $15 \mathrm{GPa}$ and then gradually to $14 \pm 3 \mathrm{~nm}$ at $55 \mathrm{GPa}$ [Fig. 2(b)]. The grain size after release of pressure is $50 \pm 7 \mathrm{~nm}$. This suggests that the grain size decrease in $\mathrm{n}-\mathrm{Ag}$ is reversible in the sense that the grain size reverts back to initial value after the release of pressure.

Similar changes in the grain sizes have been observed in many other materials. For a comparison with the present results, the data on two Au-samples [14], Pt [18], MgO [11], and Fe [13] are shown in Figs. 3(a)-(d), respectively. A reversible grain size decrease is observed in case of two Au-samples (initial grain sizes: c-Au $-120 \mathrm{~nm}$ and $\mathrm{n}-\mathrm{Au}-30 \mathrm{~nm}$ ) [14] and platinum (initial grain size - $20 \mathrm{~nm}$ ) [18] when these samples were subjected to nonhydrostatic compression in a DAC. MgO samples (initial grain size $\sim 60 \mathrm{~nm}$ ) also exhibit grain size decrease that is largely reversible [11]. The sample of Fe (initial grain size $\sim 300 \mathrm{~nm}$ ) shows a permanent decrease when subjected to nonhydrostatic compression. This behavior is similar to that observed in case of c$\mathrm{Ag}$ in this study. Not withstanding a possibility of gain refinement during the bcc-hcp transition in Fe, these two cases indicate that the solids with large grain sizes undergo permanent reduction because of severe deformation during nonhydrostatic compression in a DAC. The reversible grain size reduction largely occurs in samples with small grain sizes.

It may be mentioned that Budrovic et al. [32] observed reversible diffraction line broadening in plastically deformed nanocrystalline nickel. These authors did not separate the grain size and the strain broadening. Rather, the entire broadening was attributed to the inhomogeneous strain field. The line broadening under nonhydrostatic compression in nanocrystalline gold [14], platinum [18] and $\mathrm{n}-\mathrm{Ag}$ in this study is also reversible and qualitatively similar to those observed in nanocrystalline nickel [32]. It may be noted that initial grain size of the c-Ag is much larger (300 nm) than those of gold [14], platinum [18], nickel [32], and $\mathrm{n}$-Ag samples. The deformation of coarse-grained materials involves generation and motion of dislocation within the grains. On unloading the sample, the dislocation debris is left behind that causes a permanent increase in the line broadening. The reduction of grain-size measured by X-ray diffraction in case of nanocrystalline samples appears to arise from reversible subdivision of coherently scattering domains that are interpreted as grain size [14]. There appears to be a lower limit of grain size (a few tens of nanometers for face centered cubic metals) that can be achieved by plastic deformation under nonhydrostatic compression. In case the initial grain size of the sample is smaller than this lower limit, the grain size reduction on nonhydrostatic compression in a DAC is likely to be reversible. Much of the discussion on the reversible line broadening given by Budrovic et al. [32] appears to apply also

a

b

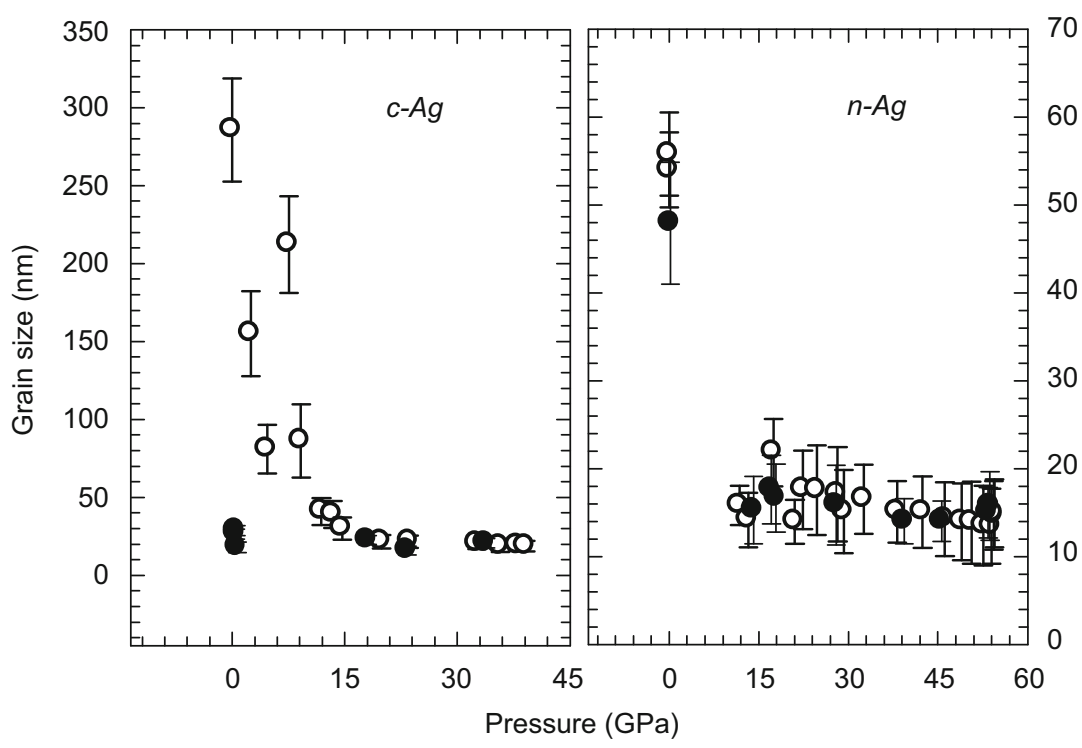

Fig. 2. The changes in the grain size of Ag under nonhydrostatic compression: (a) c-Ag and (b) n-Ag. Unfilled and filled symbols indicate data from increasing and decreasing pressure runs, respectively. 


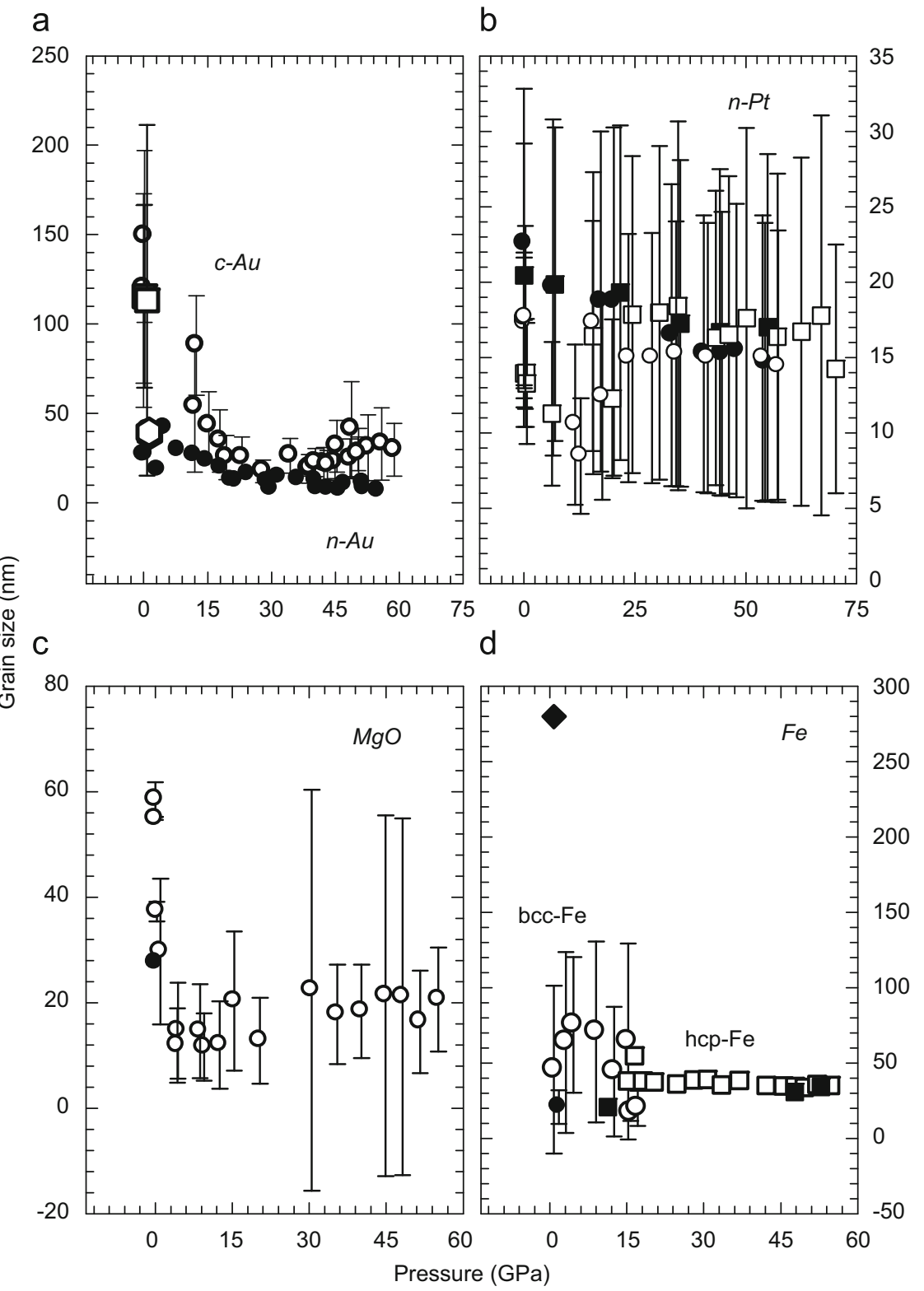

Fig. 3. The changes in the grain sizes of a few other solids of under nonhydrostatic compression: (a) c- and n-Au, (b) n-Pt, (c) MgO, and (d) Fe. Unfilled and filled symbols indicate data from increasing and decreasing pressure runs, respectively, except for (a) wherein filled and unfilled symbols indicate c-and n-Au, respectively. Large unfilled symbols in (a) show data after decompression to ambient pressure.

in case of diffraction data on nanocrystalline metals under nonhydrostatic compression.

\subsection{Compressive strength}

The strength versus pressure plots for both $\mathrm{c}-\mathrm{Ag}$ and $\mathrm{n}-\mathrm{Ag}$ are shown in Fig. 4. The strength of c-Ag increases from $0.18 \pm 0.05 \mathrm{GPa}$ at ambient pressure to $1.0 \pm 0.08 \mathrm{GPa}$ at $40 \mathrm{GPa}$. The strength at ambient pressure compares very well with the value of $0.17 \mathrm{GPa}$ for the tensile strength of fully annealed silver obtained from the conventional mechanical testing at ambient pressure [33]. The strength after decreasing the pressure from $40 \mathrm{GPa}$ to ambient is $0.32 \pm 0.07 \mathrm{GPa}$. As the grain size after pressure release is significantly smaller than the initial value, the higher strength on pressure release reflects the grain-size dependence of strength $[19,20]$. In comparison to $\mathrm{c}-\mathrm{Ag}$, the strength of $\mathrm{n}-\mathrm{Ag}$ is much higher. It increases from
$0.51 \pm 0.07 \mathrm{GPa}$ at ambient pressure to $3.5 \pm 0.4 \mathrm{GPa}$ at $55 \mathrm{GPa}$. On release of pressure to ambient, the strength drops to $0.8 \pm 0.1 \mathrm{GPa}$, which is marginally higher than the initial strength. This is not due to the grain-size effect as the grain size reverts back to the initial value on pressure release. It is likely that the locked-in stresses in the grains are stabilized by the presence of impurities in $\mathrm{n}-\mathrm{Ag}$.

The increase of strength under nonhydrostatic compression arises from two distinct factors. The first factor is the intrinsic pressure effect that is related to the shear modulus increase under pressure. The second factor is the grain-size strengthening. The exact form of the equation connecting strength with shear modulus and grain size depends on the range of grain size in the sample. For samples with grain sizes in excess of $1 \mu \mathrm{m}$, the deformation is controlled by the dislocation motion. In this grainsize range, the strength varies linearly with the shear modulus [34] and the grain-size strengthening varies linearly with $D^{-1 / 2}[19,20,35]$. The grains in the range $400-15 \mathrm{~nm}$ deform by 


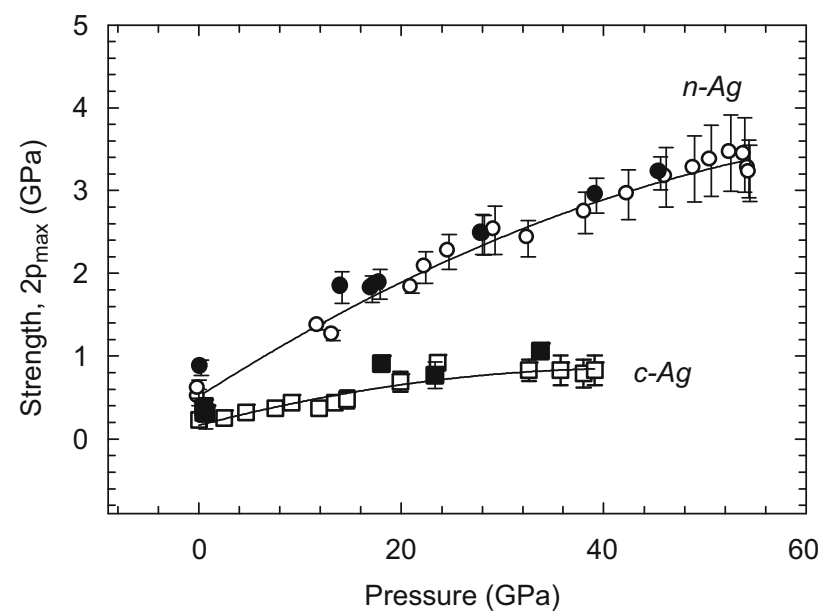

Fig. 4. The strength $\left(2 p_{\max }\right)$ as function of pressure. Unfilled and filled symbols indicate data from increasing and decreasing pressure runs, respectively.

grain-boundary shear promoted by the pileup of dislocations that are restricted to their slip planes [35]. The strength still depends linearly on $D^{-1 / 2}$ with a positive slope. This deformation mechanism is relevant to the present study as the grain size varies in the ranges 300-20 and 55-14 nm in cases of c-Ag and $\mathrm{n}-\mathrm{Ag}$, respectively. To account for the pressure effect, we divide strength by a factor $r(p)$, which is the ratio of the high to ambient pressure aggregate shear moduli. To compute $r(p)$, first the singlecrystal elastic moduli at the required pressure are computed from Eq. (4). Using these data, the shear modulus of the aggregate is computed using the Reuss-Voigt-Hill average [36]. The normalized strength $2 p_{\max } / r(p)$ contains only the grain-size effect. It is seen from Fig. 4 that the data for $\mathrm{c}-\mathrm{Ag}$ and $\mathrm{n}-\mathrm{Ag}$ lie on two distinct straight lines. The intercepts of these lines are very nearly equal but the slope of the line through the n-Ag data is nearly four times that of the line through the c-Ag data. Much higher slope of the line through $\mathrm{n}-\mathrm{Ag}$ data is due to the presence of impurities in the $\mathrm{n}-\mathrm{Ag}$ samples. Such scatter in strength versus grain-size plots and sample-to-sample differences are not uncommon. Fig. 2 in article by Conrad [35] that gives grain-size dependence of copper from a large number of studies is a typical example of large scatter. In many ambient pressure studies (e.g.[37,38] and many other references given in [35]), one-third of hardness has been taken as a measure of the yield strength. The strength data derived from the grain-size versus hardness data obtained by Qin et al. [21] are shown in Fig. 5.

The present strength data on c-Ag are in good agreement with those derived from hardness measurements. In an earlier study on $\mathrm{Au}$ [14], the strength-grain size data derived from independently measured hardness-grain size data at ambient pressure agreed well with the X-ray measured strength-grain size data. Such agreements found in case of different materials suggest that $2 p_{\max }$ is a good measure of compressive strength.

Eq. (1) and other commonly used lattice strain equations $[1-3,39-42]$ consider only the elastic strains. Recent studies $[43,44]$ have shown that a proper treatment of plastic deformation is essential for a reliable interpretation of the X-ray diffraction data. Singh [45] has shown that for the cubic system, the effects of plastic deformation and other assumptions made in the development of the lattice strain theory are adequately taken care of by suitably choosing the value of $\alpha$, a parameter that is used to derive X-ray shear modulus from the computed aggregate shear moduli under the assumptions of stress and strain continuity. A discussion given in the paper suggests that the

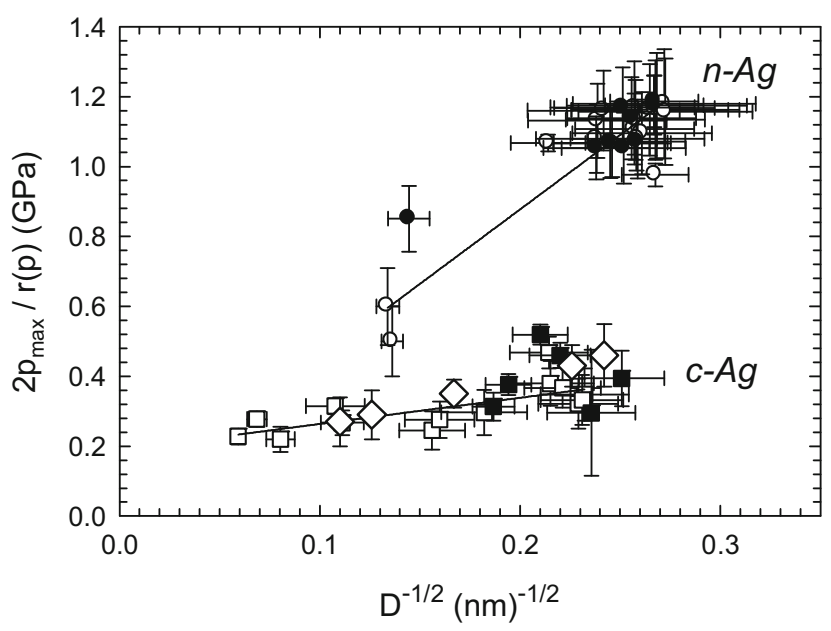

Fig. 5. The $2 p_{\max } / r(p)$ versus $D^{1 / 2}$ plot. Unfilled and filled symbols indicate data from increasing and decreasing pressure runs, respectively. Diamonds indicate data derived from the hardness versus grain size data.

strength derived from the high-pressure diffraction data are not significantly affected by the plastic deformation [45].

\section{Summary}

The c-Ag samples exhibit permanent grain-size reduction under nonhydrostatic compression in a diamond anvil cell. The $\mathrm{n}-\mathrm{Ag}$ samples undergo reversible grain-size reduction under similar compression. The reversible grain-size reduction of $\mathrm{n}-\mathrm{Ag}$ is supported by many similar observations under nonhydrostatic compression.

The strength increases with increasing pressure for both c-Ag and $\mathrm{n}-\mathrm{Ag}$. The strength corrected for pressure effect varies linearly with inverse of the square-root of grain size data and, for c-Ag, agrees well with the strength derived from the hardness versus grain-size data at ambient pressure. This agreement strengthens the view that $2 p_{\max }$ is a measure of strength.

\section{Acknowledgements}

The authors, A.J. and A.K.S., thank Director, NAL, Bangalore, for supporting this activity. The experiments were carried out at HPCAT (Sector 16), Advanced Photon Source, ANL. Use was supported by DOE-BES (Contract no. W-31-109-ENG-38), DOE-NNSA (CDAC), NSF, DOD-TACOM, and W.M. Keck Foundation.

\section{References}

[1] A.L. Ruoff, J. Appl. Phys. 46 (1975) 1389-1392.

[2] A.K. Singh, J. Phys, Chem. Solids 65 (2004) 1589-1596.

[3] R. Stokes, A.J.C. Wilson, Proc. Phys. Soc. (London) 56 (1944) 174.

[4] A.K. Singh, K. Vijayan, H. Xia, Y.K. Vohra, A.L. Ruoff, Recent Trends in High Pressure Research, in: A.K. Singh (Ed.), Proceedings of the 13th AIRAPTInternational Conference on High pressure Science and Technology, Oxford IBH, New Delhi, India, 1992, pp. 782-785.

[5] D.J. Weidner, Y. Wang, M.T. Vaughan, Science 266 (1994) 419-422.

[6] D.J. Weidner, Y. Wang, M.T. Vaughan, Geophys. Res. Lett. 21 (1994) 753-756.

[7] J. Chen, T. Inoue, D.J. Weidner, Y. Wu, M.T. Vaughan, Geophys. Res. Lett. 25 (1998) 575-578.

[8] J. Chen, T. Inoue, D.J. Weidner, Y. Wu, M.T. Vaughan, Geophys. Res. Lett. 25 (1998) 1103-1104.

[9] J. Chen, D.J. Weidner, M.T. Vaughan, Nature 419 (2002) 824.

[10] J. Chen, L. Li, D. Weidner, M. Vaughan, Phys. Earth Planet. Int. 143-144 (2004) 347-356. 
[11] A.K. Singh, H.P. Liermann, S.K. Saxena, Solid State Commun. 132 (2004) 795-798

[12] J. Chen, N. Schmidt, J. Chen, L. Wang, D.J. Weidner, J. Mater. Sci. Lett. 40 (2005) 5763-5766.

[13] A.K. Singh, A. Jain, H.P. Liermann, S.K. Saxena, J. Phys. Chem. Solids 67 (2006) 2197-2202.

[14] A.K. Singh, H.P. Liermann, S.K. Saxena, H.K. Mao, S. Usha Devij. Phys.: Condens. Matter 18 (2006) S969-S978.

[15] D. He, T.S. Duffy, Phys. Rev. B 73 (2006) 134106.

[16] A.K. Singh, H.P. Liermann, Y. Akahama, H. Kawamura, J. Appl. Phys. 101 (2007) 123526.

[17] Y. Zhao, J. Zhang, B. Clausen, T.D. Shen, G.T. Gray III, L. Wang, Nano Lett. 7 (2007) 426-432.

[18] A.K. Singh, H.P. Liermann, Y. Akahama, S.K. Saxena, E. Menendez-Proupin, J. Appl. Phys. 103 (2008) 063524.

[19] E.O. Hall, Proc. Phys. Soc. (London) B 64 (1951) 747.

[20] N.J. Petch, J. Iron Steel Inst. 174 (1953) 25.

[21] X.Y. Qin, X.J. Wu, L.D. Zhang, NanoStruct. Mater. 5 (1995) 101-110.

[22] W.B. Holzapfel, Rep. Prog. Phys. 59 (1996) 29-90.

[23] J.I. Langford, J. Appl. Crystallogr. 4 (1971) 164-168.

[24] F. Birch, J. Geophys. Res. 83 (1978) 1257-1268.

[25] W.B. Daniels, C.S. Smith, Phys. Rev. 111 (1958) 713-721.

[26] P.G. Sanders, J.A. Eastman, J.R. Weertman, Acta Mater. 45 (1997) 4019

[27] S. Rekhi, S.K. Saxena, R. Ahuja, B. Johansson, J. Hu, J. Mater. Sci. 36 (2001) 4719.
[28] B. Chen, D. Penwell, M.B. Kruger, A.F. Yue, B. Fultz, J. Appl. Phys. 89 (2001) 4794

[29] H. Liu, J. Hu, J. Shu, D. Häusermann, Ho-kwang MaoAppl. Phys. Lett. 85 (2004) 1973-1975.

[30] V.B. Shenoy, Phys. Rev. B 71 (2005) 094104.

[31] K. Takemura, J. Appl. Phys. 89 (2001) 662.

[32] Z. Budrovic, H. Van Swygenhoven, P.M. Derlet, S. Van Petegem, B. Schmitt, Science 304 (2004) 273.

[33] W.H. Cubberly, H. Baker, D. Benjamin, P.M. Unterweisser, C.W. Kirkpatrick, V. Knoll, K. Nieman, ninth ed, Metal Handbook, vol. 2, American Society for Metals, Metals Park, OH, USA, 1979 p. 672.

[34] J.O. Chua, A.L. Ruoff, J. Appl. Phys. 46 (1975) 4659-4663.

[35] H. Conrad, Metall. Mater. Trans. A 35A (2004) 2681-2695.

[36] R. Hill, Proc. Phys. Soc. (London) (A) 65 (1952) 349-354.

[37] S.H. Jhi, S.G. Louie, M.L. Cohen, J.W. Morris Jr., Phys. Rev. Lett. 87 (2001) 075503.

[38] H. Van Swygenhoven, J.R. Weertman, Mater. Today 9 (2006) 24-31.

[39] A.K. Singh, J. Appl. Phys. 73 (1993) 4278-4286 [Erratum: 74 (1993)5920].

[40] T. Uchida, N. Funamori, T. Yagi, J. Appl. Phys. 80 (1996) 739.

[41] A.K. Singh, H.K. Mao, J. Shu, R.J. Hemley, Phys. Rev. Lett. 80 (1998) 2157-2160.

[42] A.K. Singh, C. Balasingh, H.K. Mao, R.J. Hemley, J. Shu, J. Appl. Phys. 83 (1998) 7567-7575.

[43] S. Karato, Phys. Rev. B 79 (2009) 214106.

[44] S. Merkel, C. Tomé, H.-R. Wenk, Phys. Rev. B 79 (2009) 064110.

[45] A.K. Singh, J. Appl. Phys. 106 (2009) 043514. 